of conduct in relation to genetic research of this type should not only help to avoid specific problems of the type described but also help to maintain trust between families and research workers. That trust has been the basis of much of the successful research so far and must be maintained in the future if genetic advances are to be continued and used to help families with serious inherited disorders.

1 Committee on the Ethics of Gene Therapy. Report. London: HMSO, 1992.

2 Review of the guidance on the research use of fetuses and fetal material. Repon London: HMSO, 1989.

3 Committee of Inquiry into Human Fertilisation and Embryology. Report. London: HMSO, 1984.

4 Medical Research Council. Responsibility in investigations on human participants and material and on personal information. London: Medical Research Council, 1992.

5 Royal College of Physicians. Erhical issues in clinical genetics. London: Royal College of Physicians, 1991.
6 United States Department of Energy. Bibliography: ethical, legal and social implications of the human genome project. Washington DC: US Department of Energy, 1992.

7 Yates JRW, Malcolm S, Read AP. Guidelines for DNA banking. $f$ Med Genet 1989;26:245-50.

8 Firth MA. Diagnosis of Duchenne muscular dystrophy: experience of parents of sufferers. $B M \mathcal{F}^{1}$ 1983;286:700-1.

9 Brandt J, Quaid K, Folstein SE, Garber P, Maestri NE, Abbot MH, et al. Presymptomatic diagnosis of delayed-onset disease with linked DNA markers: the experience in Huntington's disease. IMM 1989;261:3108-15.

10 Morris MJ, Tyler A, Lazarou L, Meredith L, Harper PS. Problems in genetic prediction for Huntington's disease. Lancet 1989;ii:601-3.

11 Harper PS. Genetic testing and insurance. $f R$ Coll Physicians Lond 1992;26:184-7.

12 Yankner BA, Mesulan MM. B-amyloid and the pathogenesis of Alzheimer's disease. N Engl f Med 1991;325:1849-57.

13 Prusiner SB. Molecular biology of prion disease. Science 1991;252:1515-22.

14 Srivastava S, Zou Z, Pirollo K, Blattner W, Chang EH. Germ-line transmission of a mutated p 53 gene in a cancer-prone family with Li-Fraumeni syndrome. Nature 1990;348:747-9.

(Accepted 9 March 1993)

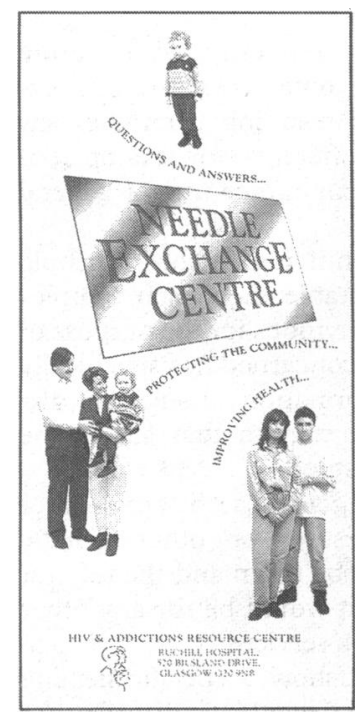

FIG 1-Leaflet produced to answer questions about needle exchanges

\title{
Building a city wide service for exchanging needles and syringes
}

\author{
Laurence Gruer, John Cameron, Lawrence Elliott
}

How best can injecting drug misusers obtain clean injecting equipment in a city where drug injecting is widespread? An exchange service for needles and syringes throughout Glasgow has been established in health centres and clinics in the evening. Over the past four years seven new exchanges have been opened and over 2700 injecting drug misusers have attended. Attendances rose from under 1000 in $\mathbf{1 9 8 8}$ to 28000 in 1992 . The exchanges also provide a wide range of other health and social services. Public hostility to the exchanges has abated. During the same period equipment sharing in the city diminished and the observed prevalence of HIV among injecting drug misusers stabilised at around $1 \%$.

Since 1987 an important part of the United Kingdom's strategy for preventing HIV infection has been the provision of sterile needles and syringes to discourage equipment sharing by drug misusers. ${ }^{1}$ The main sources of injecting equipment are community pharmacies and specialist needle exchanges. The former are cheap and informal with long opening hours but depend on the voluntary participation of the pharmacist and offer limited opportunities to provide clients with health and social services. Needle and syringe exchanges may stand alone or be part of a wider service to drug misusers. To succeed they need to be attractive and accessible. They should be close to where potential clients live and open at times they find convenient. ${ }^{2}$ In the United Kingdom, however, most needle exchange services have been operated from a single site during normal working hours. ${ }^{3}$

Glasgow is a sprawling city with a population of about 850000 . Drug injecting is common in many areas and is particularly prevalent in both deprived inner city districts and peripheral housing estates. In 1989 around 9400 people were injecting drugs, representing $1.5 \%$ of the population aged between 15 and $55 .{ }^{4} \mathrm{~A}$ pilot needle exchange began in June 1987 at Ruchill Hospital in the north of the city. The exchange opened twice weekly from 130 to $400 \mathrm{pm}$, and in line with Scottish Office guidelines three needles and syringes were offered at each visit. By December 1988 it was being attended by only $20-30$ clients each week, few of whom did so regularly. Clearly the exchange was not what most drug misusers wanted. Nor was it popular with the local community, many of whom thought it worsened the drug problem and increased the number of discarded needles. The only other legitimate source of injecting equipment was a few community pharmacists.

Given a reported $50 \%$ prevalence of HIV infection among injecting drug misusers in nearby Edinburgh ${ }^{5}$ and the diagnosis of many new cases in Glasgow, ${ }^{6}$ urgent action was required. We therefore sought to develop needle exchanges in local communities that would be acceptable to both drug misusers and the general public. Here we describe what happened over the next four years.

\section{Methods}

THE SERVICE MODEL

In January 1989 a second needle exchange was established at a drug project in a peripheral housing estate. It opened twice a week in the evenings and its success was immediate. Within a few weeks 50 clients were attending each evening. As the premises were clearly too small we asked whether the nearby health centre could be used in the evening when it was otherwise closed. Excellent facilities would thus be available without disrupting other services at the health centre. Agreement was reached and the health centre exchange opened twice weekly in May 1989 for a trial period of three months. During that time its operation was free of trouble and attendances reached 100 each evening. The opportunity to establish a network of similar exchanges within health centres and clinics throughout the city now clearly existed.

\section{ESTABLISHING NEW EXCHANGES}

It was judged that nine exchanges would ensure accessibility to drug misusers in the most seriously affected parts of the city. Once a site was selected extensive consultation was undertaken with management and staff in the premises, community organisations, local police, and social services. In most areas public meetings were held to explain the proposals and deal with anxieties and hostility, which were often deeply felt. In two areas a monitoring group of local residents was set up to examine the impact of the exchange on the community. Once local consent for an exchange had been achieved the necessary approval was sought from the minister of health at the Scottish Office.

From February 1991 health promotion officers were assigned to each operating or proposed exchange to develop community liaison. In April 1991 a leaflet designed to answer questions commonly raised about 


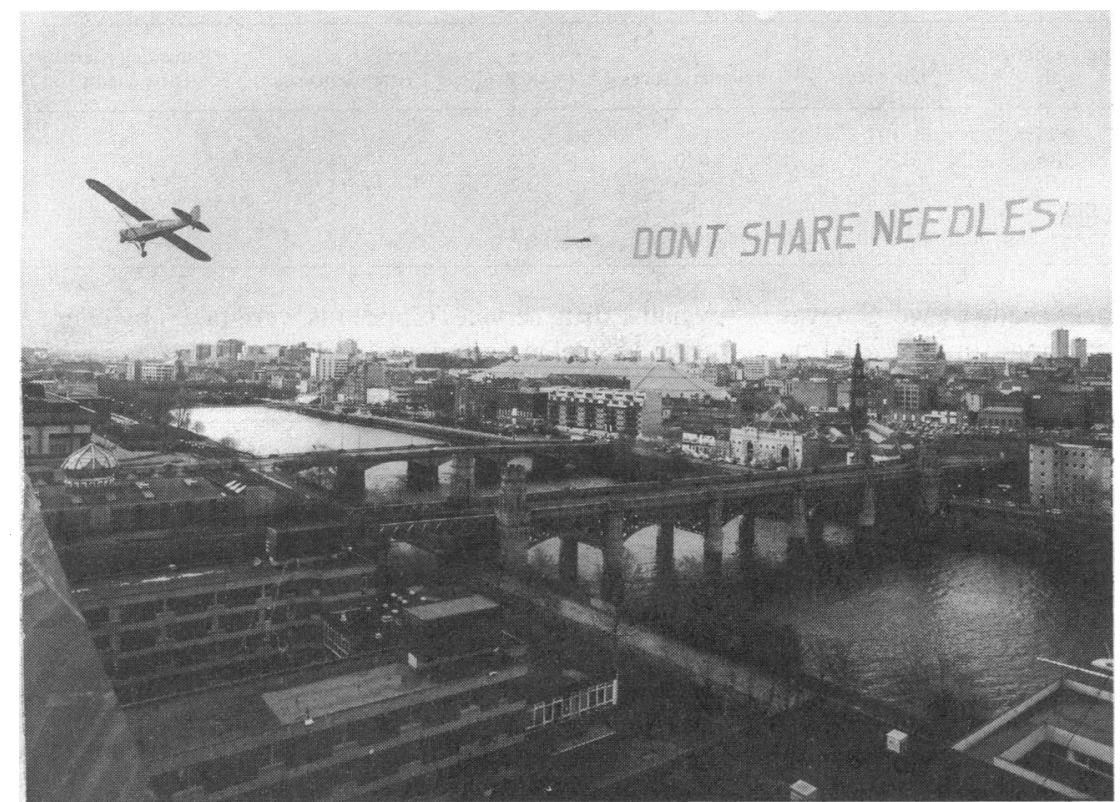

FIG 2-Publicising needle exchange service in Glasgow, World AIDS Day 1991

needle exchanges was published and widely distributed (fig 1). The media were also used to emphasise the benefits of the needle exchanges for the community as a whole and the lack of problems associated with their operation. For example, an aeroplane trailing the slogan Don't Share Needles was flown over the city on World AIDS Day 1991, successfully focusing media and public attention on the service (fig 2).

\section{STAFFING AND SERVICE DELIVERY}

Each exchange requires a waiting area, a needle exchange room, and two or more rooms for health care and counselling. It is staffed by three nurses, one of whom is a locally based health visitor, one or more local drug workers, and two or three security staff. The health visitor works during the day in the area served by the exchange. The drug workers are attached to local drug services.

New clients are given three needles and syringes at their first visit. If these are returned at the next visit six are offered and if these are returned a maximum of ten are issued, in line with revised Scottish Office guidelines. If not all the used equipment is returned less than the maximum is issued but the client never leaves empty handed. Needles and syringes are available in various sizes. Antiseptic swabs and condoms are also freely available. Clients are encouraged to take a specially designed small black plastic container with a transparent end in which to return their used equipment (fig 3).

The nurses offer advice on safer injecting and safer sex, first aid, and simple primary health care; the drug workers provide drug counselling and direct access to local services for drug misusers. All used equipment is taken for incineration as soon as possible after the clinic.

High professional standards and a good esprit de corps among the staff are sought by developing uniform operational policies; ensuring that each exchange is visited every evening by the nurse manager or his or her deputy; holding regular team meetings to update information, deal with particular topics such as sexual health, and discuss ideas for improving the service; and issuing quarterly and annual reports to all staff.

\section{AUDIT AND COSTS}

New clients are asked to give their first name and the initial of their surname, their date of birth, and the first part of their postcode. They are also asked to complete

a short questionnaire which covers their usual source of
FIG 3-Encouraging safe disposal of used injecting equipment injecting equipment; where they heard of the exchange; whether they are in contact with other drug services; their experience of prison and drug use in prison; whether they have ever had an HIV test and the date of the last test; drugs used in the last month and frequency and route of administration; and whether they have lent or borrowed used injecting equipment in the last month.

Returning clients are asked to give their first name, the initial of their surname, and date of birth. The number of needles and syringes issued is recorded exactly. The number returned is estimated as accurately as possible; this has been facilitated by the general use since 1990 of the disposal containers with transparent ends. Since 1 April 1991 all other service contacts or referrals are also recorded. Details are recorded on a standard form and then entered on to a customised program written on standard database software on a microcomputer at the HIV and Addictions Resource Centre. Quarterly and annual reports are prepared from the data and issued to all needle exchange staff and a wide range of other interested agencies and people.

The costs of the needle exchanges at 1992 prices were calculated by using information from the finance and community pharmacy departments of the Greater Glasgow health board. They included the pro rata salaries of the nurses, health visitors, and security staff and the actual costs of needles, syringes, antiseptic swabs, disposable sharps containers, condoms, and other sundries. The local drug workers are employed on a voluntary basis or paid by other agencies.

\section{Results}

From January 1989 to September 1992 seven community based needle exchanges have been opened covering most parts of the city. Efforts to open an exchange in the west of the city, however, have been delayed by local opposition. All the new exchanges are open for three to four hours in the evening on Monday or Tuesday and Thursday or Friday. The total number of hours of service rose from 250 in 1988 to 2240 in 1992. The 1992 service was equivalent to a single centre operating for nine hours, five days a week. As of December 1992 the service was managed by a clinical nurse specialist and two deputies and employed 17 health visitors and 23 other nurses on a sessional basis. One or more drug workers regularly attended each of the community exchanges or carried out streetwork to encourage misusers to attend.

The total cost of running the needle exchange service in the financial year 1991-2 was $£ 138000$, representing $£ 6.60$ per attendance and $£ 87.90$ per hour of needle exchange service. Costs were apportioned as follows: nursing salaries $65 \%$; equipment $21 \%$; security $8 \%$; transport $3 \%$; and administration $2 \%$.

\section{NEW CLIENTS AND ATTENDANCES}

Table I shows that 191 new clients attended in 1988 compared with an average of 682 a year in 1989-92. After the opening of the first community exchange total attendances rose continuously over the next few years from 880 in 1988 to 27990 in 1992 . The rate at which new clients were registered peaked at 1.2 per exchange hour in 1989 and fell over the next two years. The overall attendance rate, however, has remained steady at around 13-14 per exchange hour over the past four years, four times greater than in 1988. This reflects the much higher ratio of returning clients to new clients: in 1992 there were 36 returning clients for every new client compared with only four in 1988 . The attendance rate varied considerably from exchange to exchange, with two often being attended by more than 100 clients each evening and another seeing only 20-30. 


\begin{tabular}{|c|c|c|c|c|c|c|c|}
\hline Year & No of exchanges & $\begin{array}{c}\text { Total exchange } \\
\text { hours }\end{array}$ & New clients & Total attendances & New clients/hour & Attendances/hour & $\begin{array}{l}\text { Returning clients/ } \\
\text { new clients }\end{array}$ \\
\hline 1988 & 1 & 250 & 191 & 880 & 0.75 & 3.5 & 4 \\
\hline 1989 & 3 & 580 & 700 & 8030 & $1 \cdot 2$ & 14 & 11 \\
\hline 1990 & 4 & 1060 & 775 & 15560 & 0.75 & 14.5 & 19 \\
\hline 1991 & 5 & 1570 & 472 & 21280 & 0.3 & 13.5 & 44 \\
\hline 1992 & 8 & 2240 & 781 & 27990 & $0 \cdot 35$ & 13 & 36 \\
\hline
\end{tabular}

The proportion of all attendances made by women was $32 \%$ in both 1988 and 1992 , varying from $25 \%$ in one exchange to $33 \%$ in another. In 1992 a minibus service was operated at three exchanges to encourage those living in outlying areas to attend. This accounted for $40 \%, 29 \%$, and $8 \%$ of all attendances at the three exchanges.

Of the 781 new clients in 1992, 727 (93\%) completed the intake questionnaire. Their mean (SD) age was $26 \cdot 2(5 \cdot 1)$ years, and $75 \%$ were men. The average (SD) age at which they first injected was 18.5 (3.8) years and therefore the average period of injecting before attending the needle exchange was $7 \cdot 7$ years. Four hundred and eighty four $(66 \%)$ of the new clients had been in prison, of whom $73 \%$ had last been in prison in 1991 or 1992. Three hundred and sixty eight (51\%) new clients reported having had a test for HIV infection, of whom $77 \%$ had last been tested in 1991 or 1992 .

The commonest drugs injected were heroin, buprenorphine (Temgesic), and temazepam, injected by $61 \%, 45 \%$, and $28 \%$ respectively. Most clients regularly used at least two drugs, typically heroin or buprenorphine and a benzodiazepine. Most injected four to seven days each week and at least twice each day. Many took drugs both by injection and by mouth. Twenty per cent admitted borrowing or lending used injecting equipment during the previous month.

EQUIPMENT EXCHANGED

Table II shows that the number of needles and syringes issued increased 92-fold between 1988 and 1992. From 1990 onwards more syringes were returned than issued. The rate of return varied greatly from exchange to exchange, ranging from $90 \%$ to $220 \%$ in 1992. Many clients brought in equipment that had been acquired elsewhere, probably bought at community pharmacies. Not uncommonly clients returned several hundred used needles and syringes at a time collected from friends. On one occasion a drugs worker brought in about 5000 used needles and syringes gathered in from clients. The combination of opening the community exchanges and increasing the maximum number of needles and syringes issued from three to 10 resulted in a more than 10 -fold increase in the rate at which needles and syringes were issued.

USE OF OTHER SERVICES

During 1992 services other than needle exchange were provided during 15400 attendances. These were for primary care (54\%); advice on safer sex $(22 \%)$, safer injecting $(14 \%)$, drugs $(4 \%)$, and HIV $(1 \%)$; social services $(2 \%)$; and counselling on testing for HIV $(0 \cdot 2 \%)$. Clients were referred to other services on 1094 occasions, most often to a general practitioner or a

TABLE II-Syringes issued and returned by drug misusers attending needle exchanges

\begin{tabular}{lcccc}
\hline Year & Syringes issued & Syringes returned & $\begin{array}{c}\text { Syringes returned/ } \\
\text { syringes issued }\end{array}$ & $\begin{array}{c}\text { Syringes issued/ } \\
\text { exchange hour }\end{array}$ \\
\hline 1988 & 2600 & 2020 & $78 \%$ & 10 \\
1989 & 65100 & 60500 & $93 \%$ & 112 \\
1990 & 136900 & 143700 & $105 \%$ & 129 \\
1991 & 190000 & 235600 & $124 \%$ & 121 \\
1992 & 238500 & 273400 & $115 \%$ & 107 \\
\hline
\end{tabular}

specialist drug service. Condoms were taken by clients during $15 \%$ of attendances.

\section{Discussion}

In their review in 1988 of the pilot needle exchanges in England and Scotland, Stimson et al suggested needle exchanges should be "located in areas with a high prevalence of injecting; have ease of access both physical and psychological; have staff who are nonjudgmental; and have informal working relationships with clients." 2 They thought that exchanges should have "suitable opening hours, good relations with local media, police and community groups, and issue adequate supplies of injecting equipment." These remarks are confirmed by the growth of the needle exchange service in Glasgow once it ventured into the community, began opening in the evening, and offered more needles and syringes at each visit. There were many more new clients, a fourfold increase in the rate of attendances, improved client retention, and a 10 -fold increase in the rate at which needles and syringes were issued. The rate of return of used equipment also increased, yielding a large surplus from 1990 onwards. We believe several factors account for the surplus: the continuing important role of a small number of community pharmacists, who issued an estimated 70000-100000 needles and syringes in 1992 but do not always accept used equipment; the good rapport between staff and most clients, resulting in regular attendance; and the fair but firm policy of reducing the amount of equipment issued if insufficient is returned.

Our clients seem typical of drug misusers in Glasgow as a whole. ${ }^{47}$ In particular, the exchanges seem to be acceptable to women, who account for $32 \%$ of attendances, while an estimated $27 \%$ of injecting drug misusers in the city are women. ${ }^{4}$ Other reports have suggested a greater reluctance of women to attend needle exchanges. ${ }^{38}$ Little has been published about the efficiency or cost effectiveness of needle exchanges in making contact with drug misusers. The pilot needle exchanges in the United Kingdom recorded about one visit each hour. ${ }^{9}$ Hart et al reported up to six visits each hour at the Cleveland Street exchange in London. ${ }^{8}$ Since opening the community exchanges we have recorded 13-14 attendances each hour overall, often exceeding 30 each hour at two exchanges. The direct salary cost for each attendance at the pilot needle exchanges ranged from $£ 7.33$ to $£ 37.60$ at 1987 prices, ${ }^{8}$ compared with $£ 4.42$ for each attendance in Glasgow in 1991. The full cost of other exchanges has not to our knowledge been published. As elsewhere, the Glasgow exchanges also provide various other services and can refer clients to other agencies. This is easier when working from a fixed site rather than through mobile exchanges or outreach workers. ${ }^{1011} \mathrm{We}$ have, however, found use of a minibus helpful in bringing clients from more distant areas, thereby overcoming inertia or fear of crossing territorial boundaries.

Operating in the evenings in health centres and clinics, the exchanges offer good facilities at little extra cost without affecting other services provided there during the day. Evening opening has also enabled us to develop a pool of well trained and highly motivated staff on a sessional basis. These include general and 
psychiatric nurses from local hospitals and health visitors based in the community served by the needle exchanges. As a result there is a growing number of nurses throughout Glasgow with experience in working with drug misusers. The smooth operation of the needle exchanges has also been helpful in showing other staff in the health centres that work with drug misusers need not always cause difficulty and disorder.

Development of the service in Glasgow began in a climate of considerable public opposition to needle exchanges. This has been tackled by extensive consultation with local organisations and representatives wherever they are proposed. The need for needle exchanges, how they are run, and their impact elsewhere are carefully explained. The net inflow of used equipment to the exchanges has been helpful in allaying local residents' fears of discarded needles. This process, helped by largely sympathetic reporting in the media, has led to a clear reduction in community hostility over the past two years.

We cannot show a direct relation between the needle exchange service and the rate of spread of HIV infection, but recent trends have been encouraging. There are now few new diagnoses of HIV infection among injecting drug misusers in Glasgow and most have $\mathrm{CD} 4$ counts below $0.5 \times 10^{\circ}$ cells $/$, which suggests that infection was not recently acquired (E Galloway, personal communication). During the past six years the annual rate of seropositive patients among injecting drug misusers in Glasgow undergoing voluntary testing for HIV infection has fallen from $4 \cdot 8 \%$ to around $1 \%$ (table III). ${ }^{12}$ During 1990 and 1991 anonymous HIV testing of representative samples of about 500 Glasgow drug misusers each year yielded rates of seropositive patients of $1.4 \%$ and $0.8 \%$ respectively. ${ }^{73}$ Of these, the proportion who reported never injecting with used equipment in the previous six months rose from $57 \%$ in 1990 to $71 \%$ in $1991 .{ }^{13}$ Drug misusers who attended needle exchanges shared less often than those who did not and were less likely to report other indicators of high risk injecting. ${ }^{14}$

The needle exchange service is now established not only as a key element in the city's strategy for preventing HIV infection but also as an accepted part of mainstream community health services. Much,

TABLE III-Voluntary named testing for HIV infection of drug misusers in Glasgow

\begin{tabular}{lrrrrrr}
\hline & 1986 & 1987 & 1988 & 1989 & 1990 & 1991 \\
\hline No tested & 357 & 726 & 457 & 520 & 528 & 554 \\
No positive & 12 & 35 & 16 & 7 & 6 & 6 \\
Proportion positive (\%) & 3.4 & $4 \cdot 8$ & 3.5 & 1.3 & 1.1 & 1.1 \\
\hline
\end{tabular}

however, remains to be done. The exchanges see only about $30 \%$ of the estimated total number of injecting drug misusers. ${ }^{4}$ New cases of acute infection with hepatitis $\mathrm{B}$, particularly among young drug misusers, show that the spread of blood borne virus infection is still occurring. ${ }^{15}$ Death from overdose ${ }^{16}$ and other complications of injecting ${ }^{17}{ }^{18}$ remain common. We are therefore seeking to extend and improve the needle exchange service. Other services aimed at reducing the prevalence of drug injecting and the harm it causes are also being developed.

We thank all needle exchange staff for their tremendous work and health board management for their support. In particular, the late David Frew played a key role in establishing the first evening exchange at Easterhouse Health Centre. We also thank Alison Hardie and Sharon Duncan for their patient and meticulous data processing.

1 Advisory Council on the Misuse of Drugs. AIDS and drug misuse. Part 1. London: HMSO, 1988.

2 Stimson GB, Alldritt L, Dolan K, Donoghoe M. Syringe exchange schemes for drug users in England and Scotland. BMF 1988;286:1717-9.

3 Donoghoe MC. Syringe exchange: has it worked? Druglink 1991; i:8-11.

4 Frischer M, Bloor M, Finlay A, Goldberg D, Green S, Haw S. et al. A new method of estimating prevalence of injecting drug use in an urban method of estimating prevalence of injecting drug use in an

5 Robertson JR, Bucknall ABV, Welsby PD, Roberts JJK, Inglis JM, Penthere JF. et al. Epidemic of AIDS related virus (HLTV-III/LAV) infection among JF. et al. Epidemic of AIDS related virus (HLTV.

6 Follett EAC, McIntyre A, O'Donnell B, Clements GB, Desselberger U. HTLV-III antibody in drug abusers in the West of Scotland: the Edinburgh connection. Lancet 1986;i:446-7.

7 Haw S, Frischer M, Covell R, Finlay A, Bloor M, Follett E. et al. HIV infection and risk behaviour among injecting drug users in Glasgow. ANSWER AIDS News Supplement 1991;31:1-4. (Communicable Diseases (Scotland) weekly report.)

8 Hart G, Woodward N, Carvell A. Needle exchange in central London: operating philosophy and communication strategies. AIDS Care 1989;1: 125-34.

9 Stimson GB, Alldritt LJ, Dolan KA, Donoghoe MC, Lark RA. Injecting equipment exchange schemes, final report. London: Goldsmith's College, 1988.

10 Hartgers C, Buning EC, van Santen GW, Verster AD, Countinho RA. The impact of needle and syringe-exchange programme in Amsterdam on impact of needle and syringe-exchange p
injecting risk behaviour. AIDS 1989;3:571-6.

11 Bardsley J, Turvey J, Blatherwick J. Vancouver's needle exchange program. Can $\mathcal{I}$ Public Health 1990;82:39-45.

12 Greater Glasgow Health Board. AIDS (Control) Act Report 1991-92. Glasgow: Greater Glasgow Health Board, 1992.

13 Frischer M, Bloor M, Green S, Goldberg D, Covell R, McKeganey N, et al. Reduction in needle sharing among community-wide samples of injecting drug users. International fournal of Sexually Transmitted Disease and AIDS 1992;3:288-90.

14 Elliott $\mathrm{L}$, Frischer $M$. What distinguishes needle exchange attenders from non-attenders? Addiction (in press)

15 Gruer LD, Peedle M, Carrington D, Clements GB, Follett EA. Distribution of HIV and acute hepatitis B infection among drug injectors in Glasgow. International foumal of Sexually Transmitted Disease and AIDS 1991;2: 356-8.

16 Frischer $M$, Gruer LD. Mortality among injecting drug users in Glasgow: causes of death, the role of HIV infection and the possible impact of methadone maintenance. ANSWER AIDS News Supplement 1992;13:1-2. methadone maintenance. ANSWER AIDS News Supplement 1992;13:1-2. (Communica

17 Scott RN, Woodburn KR, Reid DB, Maraj B, Going J, Gilmour D G, et al. Intra-arterial temazepam. BMF 1992;304:1630.

18 McKeganey N, Barnard M, Leyland A, Coote I, Follett E. Female streetworking prostitution and HIV infection in Glasgow. BMF 1992;305:801-4.

(Accepted 16 February 1993)

\section{SOUND BITES}

\section{Embarrassment and sensitivity}

Some people are shy about discussing their medical problems in public and some are not. As with any conversation you tread a path between what is interesting and what might embarrass, upset, anger, or bore. Health care workers are inclined to assume that people are desensitised towards such matters.

I found myself recently sharing a hospital lift with two elderly ladies, a cheery porter, and a young man in his pyjamas. One floor up the porter turned to the young man and said, "Well, how's it going? Are you feeling better now?" The young man looked down at his feet and replied, "Yes, I'm fine, thanks." The porter then asked, "And your waterworks, are they behaving themselves?"

The question remained unanswered as the young man stood in silence, exhibiting all the signs of embarrassment: a flushed face, lowered head, and shuffling feet. The porter was just about to repeat his question when we arrived at the fifth floor. The door opened and the man in pyiamas bounded out of the lift, leaving the rest of us to continue our journey up to the seventh. "You know," said the porter, wishing to leave no gap in time unfilled, "You get to know people quite intimately in this job."

It is not only porters that start indiscreet conversations in the public arena of a hospital lift. It is easy to forget that every patient has the sole publicity rights regarding their medical complaint. At times, however, we are overcome by the lure of an interesting subject. Or more simply, we miscalculate the sensitivity of our subject matter.-SIMON HARRISON is a medical practitioner in Inverness 